\title{
Read and Speak English Online Dynamically (ReSPOnD): uma proposta de curso híbrido em língua inglesa na abordagem sala de aula invertida ${ }^{1}$
}

\author{
Susana Cristina dos Reis ${ }^{2}$ \\ Edoardo Pletsch ${ }^{3}$ \\ Programa de Pós-Graduação em Tecnologias Educacionais em Rede, \\ Universidade Federal de Santa Maria, Santa Maria, RS, Brasil
}

\begin{abstract}
Resumo: $O$ uso de metodologias ativas no ensino desafia as atuais demandas educacionais em disseminação no contexto acadêmico. Em vista disso, é urgente pensarmos em novas alternativas de materiais didáticos digitais que corroboram com tais teorias, já que ensinar línguas em uma modalidade híbrida requer também planejar conteúdos que incluam em sua gênese a inter-relação entre pressupostos teóricos e práticos. Para contribuir com essa discussão, neste artigo apresentamos um módulo de curso híbrido de língua inglesa, em que aliamos em seu design os pressupostos da sala de aula invertida (BERGMANN; SAMS, 2016) e da pedagogia de gêneros (ROSE; MARTIN, 2012). Por meio de um estudo de caso, testamos a versão piloto do curso e avaliamos a proposta. Exemplos de atividades são descritas neste artigo e os resultados iniciais mostram-se efetivos, visto que o material permitiu a prática das habilidades linguísticas de modo integrado, explorando tecnologias na modalidade invertida.
\end{abstract}

Palavras-chave: Sala de aula invertida; Material didático digital; Pedagogia de gêneros; Curso Híbrido; Língua Inglesa.

Title: Read and Speak English Online Dynamically (ReSPOnD): a blended English language course prototype in the flipped classroom approach

Abstract: The use of methodologies in language teaching challenges the current educational demands in dissemination in the academic context. Base on this, it is urgent to think in new proposals for digital learning materials that corroborate with such theories, since teaching in a blended modality; it requires planning contents that include in its genesis, the interrelationship between theoretical and practical aspects. In order to contribute to this discussion, in this article we present a digital learning material, in the form of a blended course to teaching English language, in which we include in its design the assumptions of the flipped classroom (BERGMANN; SAMS, 2016) and the genres pedagogy (ROSE, MARTIN, 2012). By applying a case study, we tested a prototype and evaluate it. Examples of challenges are presented and preliminary results are evaluated as

\footnotetext{
${ }^{1}$ Este artigo traz um recorte da dissertação de Edoardo Pletsch (2018), apresentado e defendido no Programa de Mestrado Profissional de Tecnologias Educacionais em Rede, na Universidade Federal de Santa Maria, em 15/08/2018. Devido à exigência do programa de pós-graduação, este artigo apresenta discussões sobre o produto final de dissertação no formato de Material didático digital.

${ }^{2}$ Docente no Curso de Letras-Inglês; Departamento de Letras Estrangeiras Modernas, Docente e pesquisadora no Programa de Pós-Graduação em Tecnologias Educacionais em Rede, Universidade Federal de Santa Maria. https://orcid.org/0000-0003-1697-2237

E-mail: suzireis@cead.ufsm.br

${ }^{3}$ Professor de Escola Pública; Mestre pelo Programa de Pós-Graduação em Tecnologias Educacionais em Rede, Universidade Federal de Santa Maria. https://orcid.org/0000-0002-9187-7507

E-mail: edoardopletsch@gmail.com
} 
effective, since the material allowed the practice of integrated language skills by using digital technologies in a flipped perspective.

Keywords: Flipped classroom; Digital learning material; Genre Pedagogy; Blended Course; English language.

\section{Introdução}

O ensino de língua inglesa na contemporaneidade requer práticas inovadoras tanto com relação ao material didático a ser utilizado em sala de aula quanto à abordagem pedagógica. Porém, é notável que o modelo de escola atual ainda perpasse a noção do professor como o centralizador do conhecimento, o transmissor de conteúdo e o discente como um sujeito passivo e não responsável pelos processos de ensino e de aprendizagem. Como menciona Lira (2016, p. 24), "o aluno como tábula rasa, não sabe nada, e o professor [atua] como o detentor da verdade".

Para alcançarmos a abordagem sociointeracionista e orientarmos o ensino em uma perspectiva de linguagem como prática social (VYGOTSKY, 1989; HALLIDAY, 2004), as ações pedagógicas atuais precisam ser reinventadas e renovadas com o intuito de alcançar melhores resultados de aprendizagem, e, também, potencializar a inserção das metodologias ativas no ensino (VALENTE, 2011).

A partir de nossas experiências, como docentes em sala de aula de língua inglesa, percebemos que elementos da sala de aula tradicional, como o uso do livro didático e do quadro negro, se repetem nos cenários das mais inovadoras escolas e, mesmo com o auxílio das Tecnologias Digitais da Informação e Comunicação (TDIC), muitas vezes, o ensino de línguas não alcança resultados satisfatórios (PLETSCH, 2018, p. 21).

Atrelado a isso, há também a carência de estudos no Brasil sobre a integralização de metodologias ativas com aplicação no ensino de línguas que busquem subverter a lógica tradicional e tragam o aluno para o centro dos processos de ensino e aprendizagem, tornando o professor realmente o mediador e propositor de desafios nesses processos. Tendo em mente essas premissas, buscamos implementar no design de um material didático digital atividades que dão espaço ao aluno para atuar como protagonista de sua aprendizagem e deixar o professor atuar como mediador desse processo.

Para isso, neste artigo referenciamos a pesquisa realizada por Pletsch (2018), por meio da qual procuramos respostas para as seguintes perguntas de pesquisa: como propor um material didático digital em língua inglesa, na perspectiva da sala de aula invertida, que possibilite efetivar a produção oral em uma abordagem de ensino de linguagem em gêneros? Os momentos antes, durante e após a aula, previstos na abordagem Sala de Aula Invertida (doravante SAI), são efetivos para potencializar a prática da língua adicional na modalidade híbrida? Para obtermos respostas a esses questionamentos, buscamos também descrever tarefas/gêneros que pudessem ser efetivos para alcançar tais objetivos. 
No nosso grupo de pesquisa GRPesq/CNPq - Núcleo de Pesquisa, Ensino e Aprendizagem de Línguas a Distância (NuPEAD), as pesquisas reportam diferentes eixos na área de CALL (REIS, 2010; 2012) que incluem desde entender como a linguagem se constitui em diferentes gêneros discursivos ou multimodais, bem como investigamos como o uso de certos recursos tecnológicos (por exemplo, softwares/ferramentas, ambientes virtuais, aplicativos, etc.), podem potencializar os processos de Ensino e Aprendizagem de línguas na modalidade a distância (NuPEAD, 2017).

Com a intenção de contribuir com as pesquisas do grupo, neste artigo apresentamos uma proposta de curso de língua inglesa - Read and Speak English Online Dynamically (ReSPOnd), módulo pré-intermediário, com foco na abordagem de sala de aula invertida, desenvolvido para ser aplicado no contexto universitário (PLETSCH, 2018). O ReSPOnd faz parte dos cursos de extensão, ofertados pelo Projeto LabEON (Laboratório de Ensino e Aprendizagem de Línguas Online), e dá continuidade aos módulos básicos I e II do English Online.

Para apresentarmos o curso, primeiramente dissertaremos sobre a produção de material didático digital para o ensino de línguas e as etapas cíclicas que fomentaram a construção da proposta; na sequência, abordamos a perspectiva de gênero adotada para orientar as atividades e os conteúdos, bem como as concepções sobre ensino híbrido e os pressupostos sobre sala de aula invertida que nortearam o desenvolvimento do produto no formato de material didático digital.

\section{Produção de Material Didático Digital para o ensino de Línguas na modalidade híbrida e na perspectiva de gêneros}

Publicações sobre produção de Material Didático Digital (doravante MDD), no contexto universitário, têm sido investigados por diferentes pesquisadores, entre eles podemos citar Filatro (2008), Behar (2009), Moore (2013), Reis e Gomes (2014), entre outros. A necessidade de mais investigação sobre essa temática, motivou os membros do NUPEAD intensificarem a pesquisa e a produção de MDD a partir dos resultados mensurados e publicados. Os estudos de Cecchin (2016); Cecchin e Reis (2016), Gomes (2017), por exemplo, são usados como referências para este artigo, já que validaram o modelo cíclico de MDD, proposto por Reis e Gomes (2014, p. 372), testando-o ao elaborarem diferentes propostas de cursos online nos últimos anos.

De acordo com Reis (2018), o modelo cíclico parte de estudos de Allen (2006), mais especificamente, do modelo $\mathrm{ADDIE}^{4}$ e das discussões teóricas sobre material didático encontradas no livro de Leffa (2008). Reis e Gomes (2014) ao analisarem esses pressupostos

\footnotetext{
${ }^{4}$ Segundo Allen (2006), este é o modelo de design instrucional que instrui os processos para a produção de material didático, o qual prevê as seguintes etapas: Análise, Design, Desenvolvimento, Implementação e avaliação.
} 
perceberam que ao produzir MDD essas etapas devem ser cíclicas, visando à elaboração do produto tecnológico, de modo sistemático. Para os autores, essas etapas também são distintas e se interconectam formando um caminho para a produção do material. Portanto, os autores sugerem para orientar o design as seguintes etapas: Análise, Planejamento, Design da Interface, Testagem piloto, Redesign da Interface, Aplicação e Avaliação.

Ao propor MDD para o ensino híbrido, Reis e Gomes (2014) afirmam que é primordial ficar atento primeiramente ao público alvo. A etapa Análise é o momento inicial de desenvolvimento e consiste em analisar o público e o contexto em que o material será aplicado. Para isso, uma pesquisa de diagnóstico deve ser feita por meio de questionários ou, ainda, por outros instrumentos que identifiquem o interesse do público. Consciente do público alvo e da proposta a ser desenvolvida, inicia-se o planejamento.

A etapa Planejamento é o momento em que a equipe de desenvolvimento busca discutir por qual meio e formato o MDD será disponibilizado. Tendo por base os dados de análise coletados na etapa de análise e definidos os pressupostos que fundamentam o material a ser elaborado, busca-se planejar o programa do curso ou do material, incluindo nessa previsão, por exemplo, os conteúdos/tópicos, as habilidades/competências linguísticas a serem praticadas, bem como as ferramentas/mídias que serão exploradas em tal material.

Em Design da interface, com base nos dados coletados, elabora-se o MDD desenvolvendo a interface digital gráfica do material (conteúdo e gráfico) em um ambiente virtual de aprendizagem. Após surgir a primeira versão, faz-se necessário proceder para a Testagem. Nesse momento é essencial testar o produto piloto (ou protótipo), antes da aplicação do material/curso na sua versão final.

Nessa etapa, também, é essencial coletamos dados por meio de questionários avaliativos, a fim de averiguarmos se a proposta foi efetiva quanto aos objetivos planejados para o curso/material. Feita a avaliação, teremos a etapa (Re)design da interface, após a aplicação do primeiro piloto. Nesse momento, volta-se a atenção ao feedback oferecido pelos participantes anteriormente, para avaliar quanto à interface gráfica e aos conteúdos, as interações estabelecidas por meio do recurso para, se necessário, reformular o produto, aperfeiçoando-o, com o intuito de dirimir problemas detectados.

A etapa Aplicação dá continuidade à execução da proposta de curso (ou de MDD), seja com o mesmo público, em nova edição, ou, ainda, com outros sujeitos com mesmo perfil. Na etapa Avaliação, de posse de todo o feedback recebido, reinicia-se o ciclo considerando os resultados obtidos com vistas a verificar o que se efetivou como o planejado e o que não funcionou e o porquê.

Essas discussões reforçam que o desenvolvimento de MDD precisa obedecer aos critérios de desenvolvimento, pois são estes que norteiam a proposta a fim de pautar e garantir a construção clara, concisa e coesa. Sob esse aspecto, é possível incluir a necessidade de pensar na concepção da linguagem, bem como nas concepções de ensino e de aprendizagem que fundamentam a proposta de material didático (REIS, 2017; 2018). Na 
sequência, abordaremos sobre as concepções que orientaram o desenvolvimento do curso ReSPond que será apresentado na seção de análise.

\section{Concepções de linguagem, ensino e de aprendizagem que fundamentam o design de MDD}

Na nossa prática docente, recorrentemente evidenciamos que, em sala de aula, muitos professores negligenciam os conhecimentos prévios do público alvo com que atuam, não questionando previamente sobre as atividades e as práticas sociais em que tais alunos se engajam (REIS, 2010; 2014; 2017; CECCHIN, 2015; CECCHIN; REIS, 2016; PLETSCH, 2018). Além disso, é perceptível que, muitas vezes, os professores não têm clareza sobre as concepções de linguagem, ensino e aprendizagem que norteiam sua prática docente (REIS, 2018).

Tendo isso em vista, sugerimos que antes de começar o planejamento de um MDD, é fundamental a(o) professor(a), primeiramente conhecer melhor, não apenas o seu público alvo e contexto de atuação (a exemplo da infraestrutura disponível e os recursos), bem como a si mesmo, ao definir suas concepções de linguagem, ensino e aprendizagem que embasam sua práxis para posteriormente incluir tais pressupostos na proposta de materiais a ser desenhado e aplicado (REIS, GOMES, 2014; REIS, 2017; 2018).

No nosso estudo, para propormos um MDD, com foco no ensino de línguas para a modalidade híbrida, na perspectiva da pedagogia de gêneros, consideramos a concepção de linguagem como prática social (MOTTA-ROTH, 2006, 2008; ROSE; MARTIN, 2012; HALLIDAY; HASSAN, 1989), para isso analisamos os pressupostos teóricos e, também, estudos sobre ensino híbrido e sala de aula invertida (VALENTE 2015; BOTTENTUIT, et al., 2017; BACICH et al., 2015), antes de iniciarmos o processo de produção do material digital.

Nessa perspectiva teórica, entendemos que ao explorarmos o gênero em estudo, buscaremos trabalhar as atividades do curso em etapas/estágios, pois conforme indicam Rose e Martin (2012, p. 1, tradução nossa), gêneros são "estágios orientados por um processo social com vista a atingir um objetivo". As experiências de pesquisa de Rose e Martin (2012) resultaram no ciclo de ensino e aprendizagem, e as três etapas propostas pelos autores, desconstrução, construção conjunta e independente do gênero levam o estudante a refletir acerca do uso da linguagem, apropriando-se dela a partir da análise de exemplares para posteriormente produzir novos textos (PLETSCH, 2018).

Compreender os gêneros e as diferentes situações comunicativas de uso da linguagem, com a finalidade de desenvolver as habilidades necessárias para interação na língua adicional, perpassa desconstruí-los pela análise contextual de exemplares, identificando seus estágios, discutindo o processo social de produção e de consumo, com o propósito de conduzir o aluno a refletir sobre a função social e os aspectos linguísticos do 
gênero em estudo, refletindo de modo colaborativo com o aluno sobre o processo de produção, de consumo e de distribuição (MOTTA-ROTH, 2008).

Segundo Halliday (2004, p. 3, tradução nossa), ao adotarmos a concepção de linguagem como social devemos considerar que o aluno deverá fazer uso da língua que se apresenta por meio de texto em atividades sociais e em gêneros que se apresentam nas diversas esferas sociais (MOTTA-ROTH, 2006). Motta-Roth (2006, p. 3) ainda adiciona que "gêneros são entendidos como atividades culturalmente pertinentes, mediadas pela linguagem num dado contexto de situação, atravessado por discursos de ordens diversas". Por isso, é preciso pensar em atividades socialmente significativas a fim de engajar o aluno em diferentes contextos e gêneros em circulação social, consequentemente desenvolvendo as habilidades de forma integrada (PLETSCH, 2018; REIS, 2018).

Ao planejarmos MDD para o ensino de língua inglesa, consideramos os conceitos previamente supracitados que balizam o presente estudo. Entendemos que um MDD deve ser lido como um conjunto de textos que signifiquem ao aluno, para que sejam catalisadores para o pensamento crítico e que fomentem o entendimento da realidade circundante, para além de reproduzi-la em diferentes contextos, entendê-la e perceber o objetivo comunicativo em diferentes instâncias (PLETSCH, 2018; REIS; 2018).

Portanto, no design do ReSPOnD pensamos em tarefas/desafios, que dão ao professor o papel de mediador das práticas de ensino e aprendizagem. Como sugere Halliday e Hassan (1989, p.5, tradução nossa) aprender é "acima de tudo, um processo social [...] e conhecimento é transmitido em contextos sociais, através de relações como as de pais e filhos, colegas". Se entendermos prática social como "maneiras habituais, associadas a tempos e lugares específicos, nas quais as pessoas aplicam recursos (materiais ou simbólicos) para agir em conjunto no mundo" (MOTTA-ROTH, 2008, p. 246), portanto, é importante pensarmos em ações, atividades sociais que possam engajar o aluno no intuito de aprender a língua.

Para isso, tomamos a sala de aula como um ambiente de prática social, nela o discente/docente transita e marca-se no contexto que circula (PLETSCH, 2018). Portanto, para o ReSPond concebemos que este deve ser pensado de maneira a abarcar as diferentes esferas de atividade (contexto educacional, trabalho, social, entre outros) em que os participantes se identifiquem em uma prática social, a fim de promover aprendizagem significativa (GEE, 2005).

\section{Integração de modalidades e princípios da sala de aula invertida no design do MDD}

Para promover a modalidade híbrida na educação, como salienta Moran (2015, p. 27), é preciso combinar "vários espaços, tempos, atividades, metodologias, públicos". Portanto, tomando como exemplo uma sala de aula qualquer, podemos inferir que naquela 
instância de prática social, a aula é híbrida quando o professor mistura metodologias de aprendizagem, integrando no seu planejamento, por exemplo, um trabalho em grupo com momentos expositivos dialogados ou, ainda, realizando a aula no pátio da escola mesclada com a sala tradicional (MORAN, 2015).

O autor ainda infere que a modalidade híbrida é essencial para escolas que adotam modelos pedagógicos mais inovadores, baseados em problemas e projetos; sejam estes colaborativos ou que tenham um foco na construção do projeto de vida dos seus alunos, bem como considerando abordagens com ênfase nas competências (MORAN, 2015). Na mesma linha de pensamento, Cristensen et al (2013) esclarecem que o ensino híbrido 5 :

é um programa de educação formal no qual o aluno aprende, pelo menos em parte, por meio do ensino on-line com algum elemento de controle do estudante sobre o tempo, lugar, modo e ou ritmo do estudo, e pelo menos em parte em uma localidade física supervisionada, fora de sua residência. (CHRISTENSEN et al., 2013, p. 8).

Com isso, depreendemos que em uma modalidade híbrida devemos misturar espaços e modalidades. Na opinião de Bacich et al (2015), os autores indicam que com a recorrência do uso das tecnologias na educação, o ensino híbrido se apresenta em dois modelos de aprendizagem: o modelo presencial, em que o processo ocorre em sala de aula, como vem sendo realizado há muitos anos e, o modelo on-line que utiliza as TDIC para promover o ensino. Portanto, consideramos que esses dois ambientes de aprendizagem sala de aula tradicional e o espaço virtual - tornam-se gradativamente complementares. (BACICH et al., p. 52).

Tendo como premissa que a modalidade híbrida comporta, simultaneamente, o presencial e o on-line, não podemos relegar a importância do professor como orientador e mediador de aprendizagem significativa (MORAN, 2015). Nesse sentido, ao misturar metodologias de ensino e ao trazer o conteúdo on-line para a sala de aula, o professor deverá desempenhar o papel de mediador ao orientar o trabalho de forma conjunta. 0 profissional que mistura metodologias precisa preparar-se e ter expertise de como fazê-lo e, da mesma forma, guiar o discente por meio da abordagem adotada (PLETSCH, 2018).

Entre os modelos de modalidade híbrida, atualmente em discussão, está a sala de aula invertida (doravante SAI). Apesar de não ser um termo recente - a SAl tem seus primeiros registros no ano 2000, conforme proposto por Lage, Platt e Treglia (2000). Porém, tal abordagem tornou-se expoente após publicação de Jonathan Bergman e Aron Sams (2016), pelo sucesso atrelado a implementação dessa abordagem em suas aulas (VALENTE, 2015; BOTTENTUIT, et al., 2017; BACICH et al., 2015).

\footnotetext{
${ }^{5}$ Neste artigo, adotaremos o termo modalidade híbrida quando nos referirmos a ensino híbrido.
} 
Para Bottentuit Junior et al. (2017), a sala de aula invertida pressupõe um ambiente de reflexão sobre o que o professor, a priori, disponibilizou em vídeo e será assistido em casa. Os estudantes trazem então, para a aula questões pertinentes àquele conteúdo proposto. O espaço destinado ao docente fica agora para interação do professor com os alunos, desafiando-os à resolução das tarefas colaborativas ou a resolução de atividades de pesquisa e de solução de problemas. Ainda, Bottentuit Junior (2017) menciona que nessa abordagem, o foco é o aluno, descentralizando o professor.

Segundo Bergmann e Sam (2016) relatam, na perspectiva da sala de aula invertida, o tempo gasto verbalizando o conteúdo é gasto nos momentos de discussão com os alunos sobre o tema em foco. Invertem-se os papéis. Na mesma direção, Mazon (2015) afirma que essa abordagem se orienta por três princípios, ou seja:

fornecer conteúdo e instruções com antecedência para os alunos se prepararem antes de ir para a aula; [promover a] Cultura de aprendizagem [...] motivar os alunos a serem os protagonistas do seu próprio aprendizado; [elaborar] Aulas participativas, incluindo perguntas, discussões e aplicações práticas dos conceitos aprendidos. (MAZON, 2015, p. 126, grifo nosso).

A sala de aula, na modalidade híbrida, pode fomentar o uso das tecnologias a fim de utilizar o que se tem de melhor no contexto escolar. Como indica Schneider (2015, p. 71) "o conhecimento acontece quando algo faz sentido, quando é experimentado, quando pode ser aplicado de alguma forma ou em algum momento". Esse movimento de gerar conteúdo sensível à realidade social e cultural do aluno possibilita "maximizar a capacidade de aprendizagem do estudante" (SCHNEIDER, 2015, p. 71), portanto, é imprescindível em aula quebrarmos o ciclo de monotonia do ensino regular tradicional.

Ao considerarmos tais pressupostos, entendemos que inverter a sala de aula é uma estratégia pedagógica que subverte o ensino a que muitos estão acostumados. Por isso, ao propor um material didático digital que inclua em seu design tais princípios, é preciso planejar uma proposta que coloque o aluno no centro do processo e o desafie a inserir-se nessa nova cultura de aprender de modo muito mais autônomo.

\section{Metodologia}

A presente pesquisa é de natureza aplicada, de caráter exploratório e quanto aos procedimentos trata-se de um estudo de caso (YIN, 2001). A análise dos dados adotou uma abordagem de natureza qualitativa. Para isso, foi submetida ao comitê de ética e recebeu parecer favorável sob número de registro 72074217.4 .0000 .5346 para sua execução. Em vista disso, buscamos preservar a identidade dos participantes considerando a ética no 
trabalho realizado. O projeto foi registrado no Gabinete de projetos $\left(\operatorname{GAP}^{6}\right)$, do Centro de Artes e Letras, da UFSM.

Os dados foram coletados por meio das ações do Grupo de Pesquisa - GRPesq Núcleo de Pesquisa, Ensino e Aprendizagem de Línguas a Distância (NuPEAD), na Universidade Federal de Santa Maria (UFSM), mais especificamente, nas atividades de extensão do projeto Laboratório Virtual de Ensino e Aprendizagem de Línguas Online (LabEOn). Os dados coletados pela aplicação de questionário diagnóstico, junto à comunidade acadêmica da UFSM, permitiram identificarmos o interesse do público-alvo para elaborarmos novos cursos na modalidade híbrida ou EaD.

Tivemos dois tipos de participantes envolvidos durante a coleta. Os participantes, denominados como "participante pré-planejamento" (PPla), sendo que destes 30 participantes responderam questionários diagnósticos, em julho de 2017, cujos dados obtidos nos ajudaram a planejar o curso. Em abril de 2018, aplicamos um novo questionário para selecionarmos os participantes com o mesmo perfil dos PPla para testagem da versão piloto do curso.

Os critérios para seleção dos participantes para testagem (Ptest) incluíam: a) realizar um teste de nivelamento para identificar sua proficiência linguística ou ter sido aluno de um dos cursos de extensão oferecidos pelo laboratório, por exemplo, de um dos módulos (I ou II) do English Online ?. Foram selecionados como Ptest 14 alunos universitários para realizarem as atividades propostas na versão piloto do ReSPOnD.

Outros instrumentos de coleta de dados utilizados foram diários de campo e registros em filmagens para anotações das interações aluno e professor, bem como por meio dos feedbacks dos discentes perante a execução das atividades e aplicação de questionário avaliativo.

Neste artigo, fazemos um recorte desses dados e buscamos avaliar: a) as atividades propostas considerando os momentos proposto pela sala de aula invertida, por exemplo, se o momento Before Class foi estudado antes da aula presencial; b) verificar se os participantes interagiam na aula presencial (During Class) e c) verificar a postagem e efetiva participação dos alunos Ptest no momento After Class, bem como identificar uma avaliação inicial sobre a proposta implementada.

\footnotetext{
${ }^{6}$ Registrado sob o número 045250.

${ }^{7}$ English online ou English Online 3D é o nome do curso híbrido ofertado pelo projeto Laboratório de Ensino e Aprendizagem de Línguas Online. Esse curso foi criado em 2012 e tem por objetivo promover o uso da língua por meio de atividades mediadas por tecnologias, a fim de potencializar a aprendizagem e a comunicação em língua inglesa. Além disso, busca-se favorecer a prática de Multiletramentos ao realizar desafios por meio da interação virtual na plataforma Moodle (REIS; LINCK; MATTIELLO, 2012).
} 


\section{Descrição do produto ReSPOnD - Read and Speak Online Dynamically}

Os dados gerados pelo questionário diagnóstico permitiram o planejamento do curso ReSPOnD ${ }^{8}$. Esse curso é um módulo de língua inglesa, em nível pré-intermediário, proposto para ser ministrado na modalidade híbrida, utilizando a abordagem sala de aula invertida (JONATHAN; BERGMANN, 2016; VALENTE, 2015; BOTTENTUIT, et al., 2017; BACICH et al., 2015).

O curso foi hospedado no ambiente e no domínio da Universidade Federal de Santa Maria (UFSM) e possui três estágios temáticos. Tem por objetivo desenvolver as habilidades linguísticas de produção oral, leitura, escrita e compreensão oral, de forma integrada, no ambiente virtual de ensino e aprendizagem Moodle. Na figura 1 ilustramos a estrutura do curso.

Figura 1 - Identidade visual do curso

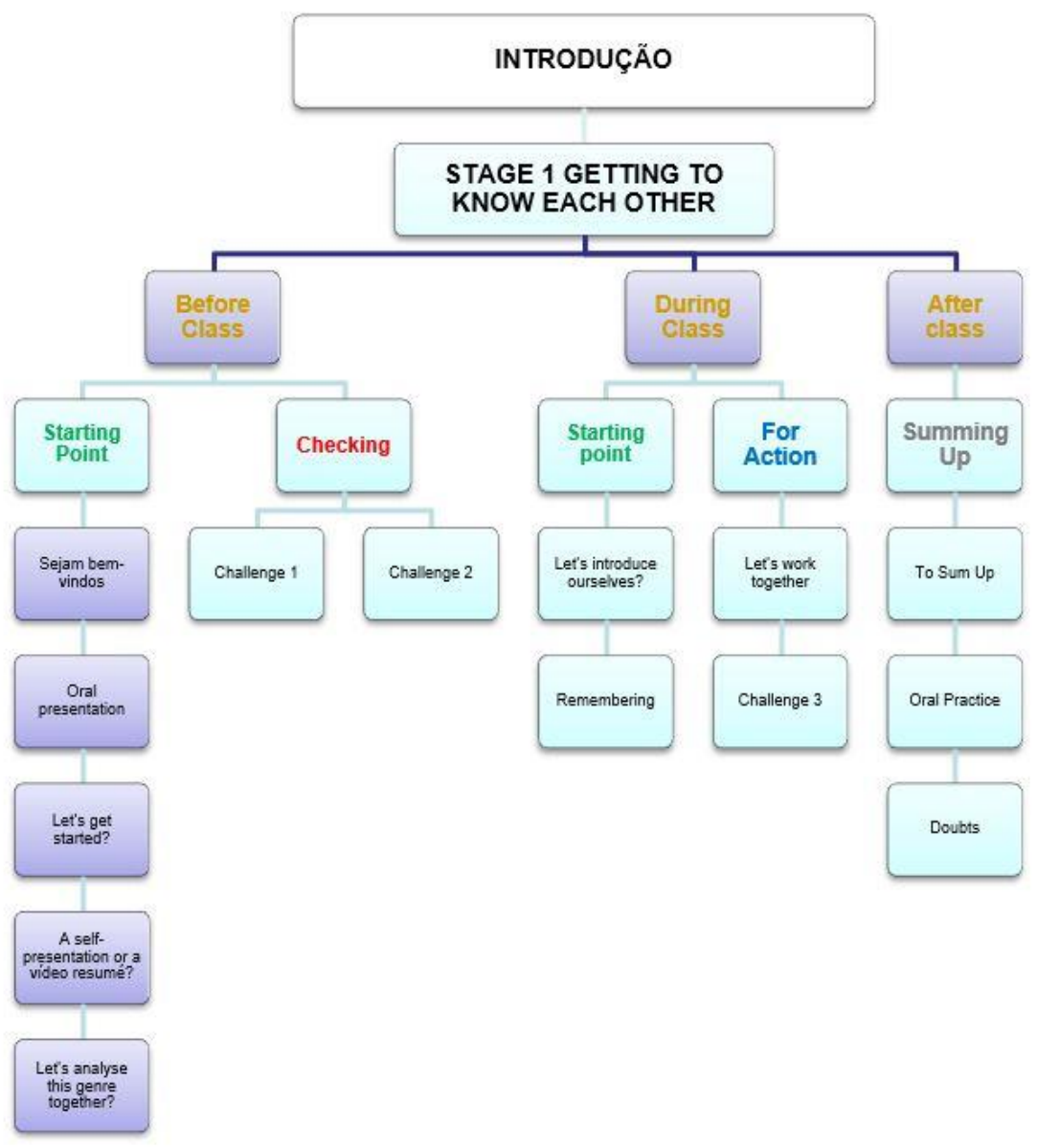

Fonte: ReSPOnD - Banco de dados NuPEAD (2018)

\footnotetext{
${ }^{8}$ A sigla significa Read and Speak Online Dynamically, conforme supracitado na introdução deste artigo.
} 
O módulo proposto ancora-se, também, nos pressupostos teóricos da pedagogia de gêneros (ROSE; MARTIN, 2012) e na concepção de linguagem como prática social (MOTTAROTH, 2006, 2008), que propõe explorar gêneros, por meio de uma abordagem cíclica e continua de aprendizagem, por meio da promoção de atividades de produção conjunta e individual. As atividades são elaboradas considerando os estágios de desconstrução do gênero, construção conjunta e construção individual (ROSE; MARTIN, 2012).

Além disso, no curso os momentos planejados com relação à sala de aula invertida são: Before class, During Class e After class. Ao adotarmos esses pressupostos para inclui no design do material, o momento Before Class é o que conta com maior número de atividades, pois, é nesse espaço que o aluno deve ter o maior contato com o material de estudo. 0 During Class apresenta atividades colaborativas enquanto que o After Class traz atividades individuais.

A versão piloto do ReSPOnD divide-se em três estágios temáticos que abordam, por exemplo, os tópicos: Getting to know each other; Speaking and Editing, e Interviewing. 0 Getting to know each other permite ao aluno estudar os gêneros Perfil e Vídeo Résumé; o Speaking and Editing explora a elaboração do Vídeo Résumé; e o Interviewing propõe os gêneros entrevista de auditório e de emprego.

Para ilustrarmos como desenhamos a interface gráfica do curso, apresentamos algumas telas que trazem o MDD encontrado no ambiente Moodle (http://nte.ufsm.br). A figura 2 mostra a identidade visual do estágio um, Getting to know each other, mais especificamente da tela inicial do MDD. Nesse estágio, as atividades propostas no Starting Point é o momento anterior a aula prática presencial, em que se apresenta o gênero e sincroniza com a etapa da sala de aula invertida.

O momento da apresentação do material necessário ao estudo é chamado de Before Class, ou seja, é previsto contato com o conteúdo antes da aula presencial. Para descrevermos um pouco mais sobre o produto, na sequência detalhamos alguns conteúdos e atividades propostas. 
Figura 2 - Identidade visual, estágio um - Getting to know each other

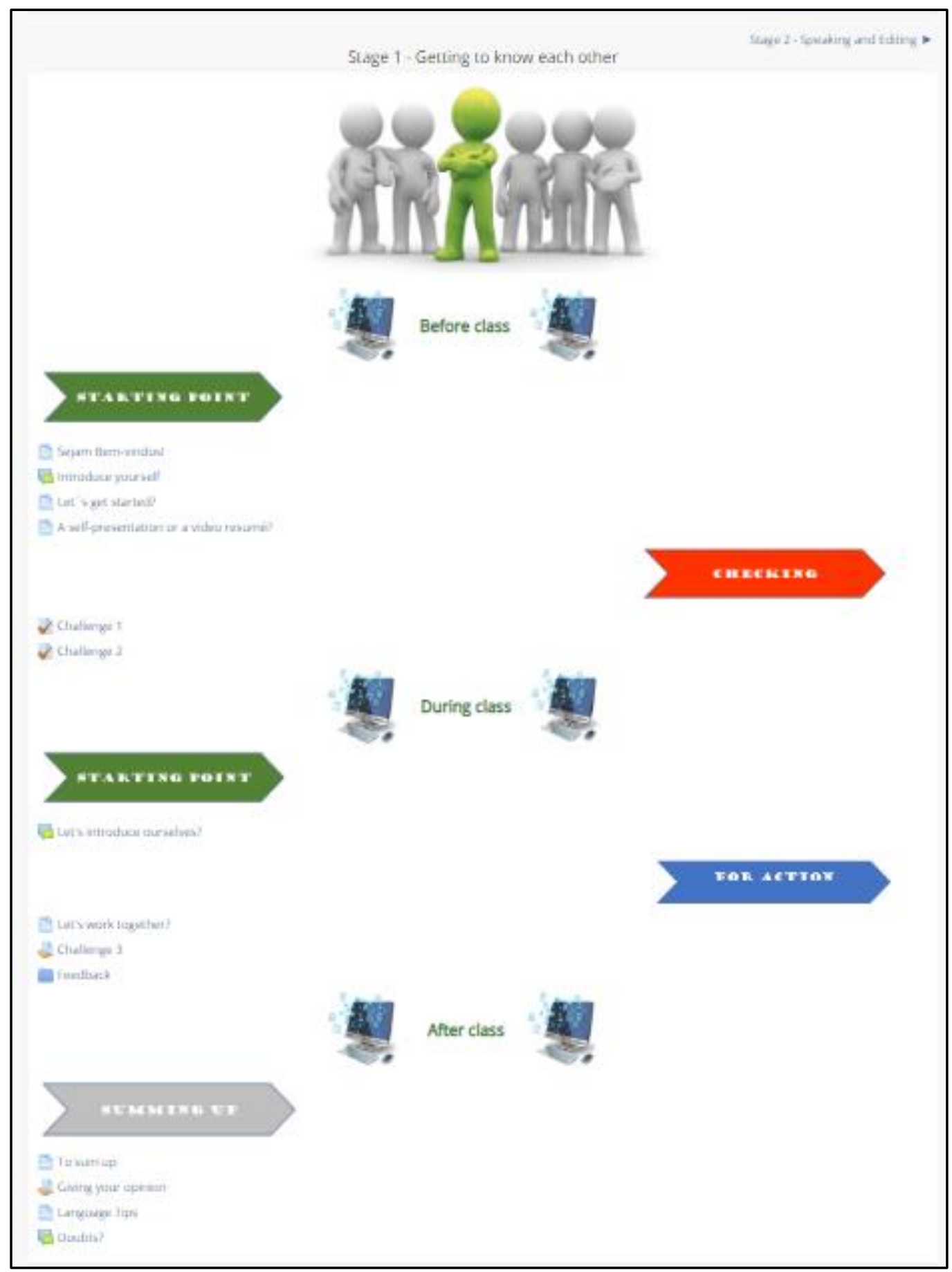

Fonte: ReSPOnD - Banco de dados NuPEAD (2018)

Por exemplo, na atividade de fórum Introduce Yourself propomos ao aluno um desafio quanto a sua apresentação pessoal, utilizando a ferramenta Online Voice Recorder. 0 objetivo era conhecer o aluno de maneira informal, sem qualquer informação ainda sobre os gêneros a serem trabalhados nesse nível, conforme ilustra a Figura 3. 
Figura 3 - Exemplo de Atividade/challenge Introduce Yourself

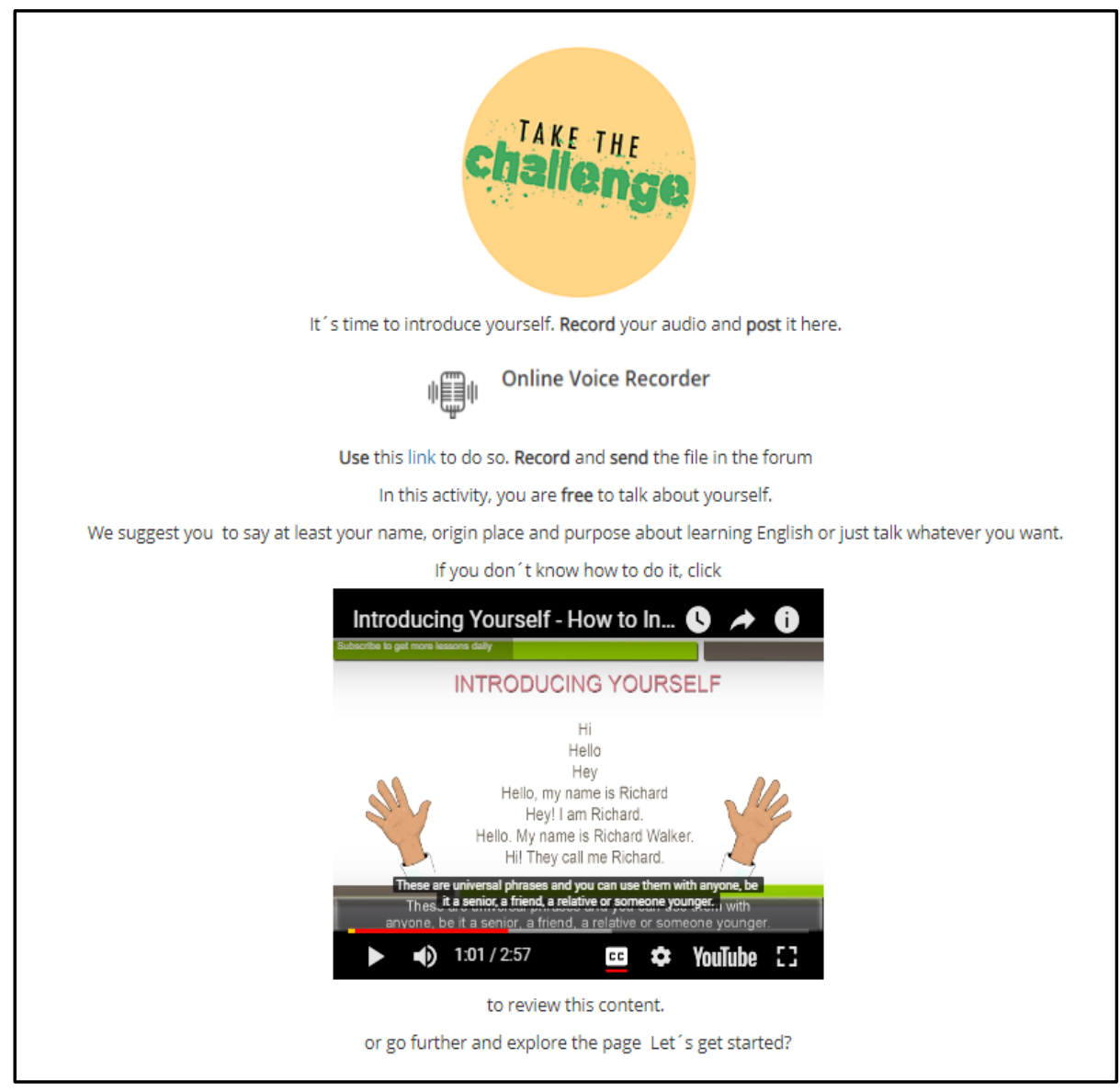

Fonte: ReSPonD - Banco de dados NuPEAD (2018)

Entendemos que essa seria a maneira de conhecer o que nossos alunos já sabiam e, também, buscar ativar o conhecimento prévio dos participantes quanto à língua adicional, levando-os a perceber o que já sabem sobre o assunto/tópico em estudo. Outro exemplo de atividade é o que encontramos na página Let's Get Started (ver Figura 4), em que indicamos aos alunos para que assistam a um vídeo de apresentação de um estudante.

A intenção nesse momento é contextualizar o aluno ao provocá-lo com alguns questionamentos acerca do objetivo do vídeo, a fim de identificar os participantes envolvidos, o nível de linguagem (formal, informal), bem como verificar o entendimento linguístico dos alunos, preparando-o para o conteúdo seguinte. Para isso, elaboramos questões norteadoras orientando a leitura e a compreensão oral do vídeo proposto. Ao acessá-lo e compreendê-lo, esperávamos que o aluno fizesse anotações de vocabulários/novas palavras, sintetizasse informações que ele conseguisse inferir e, assim estabelecesse um primeiro contato com o material. 
Figura 4 - Exemplo de atividade/challenge - Let's get started?

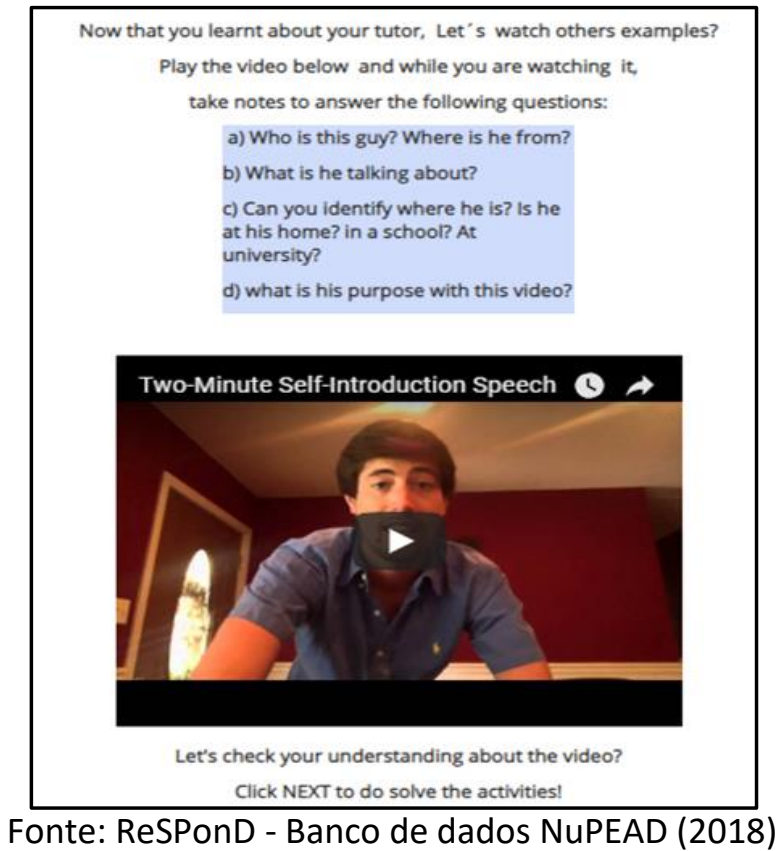

A proposta na página self presentation or a video résumé tinha o intuito de fazer o aluno refletir sobre as diferenças entre uma self-presentation e um vídeo résumé, antes de ele ir para aula presencial. Para isso, conduzimos o aluno-leitor a identificar o propósito do vídeo, os participantes envolvidos na interação apresentada, a mensagem veiculada, e a possível audiência. Após a compreensão e leitura do material proposto, apresentamos o primeiro Challenge ao aluno, visando explorar o entendimento sobre o conteúdo do vídeo proposto.

Figura 5 - Exemplo de atividade/Challenge explorando a compreensão do aluno

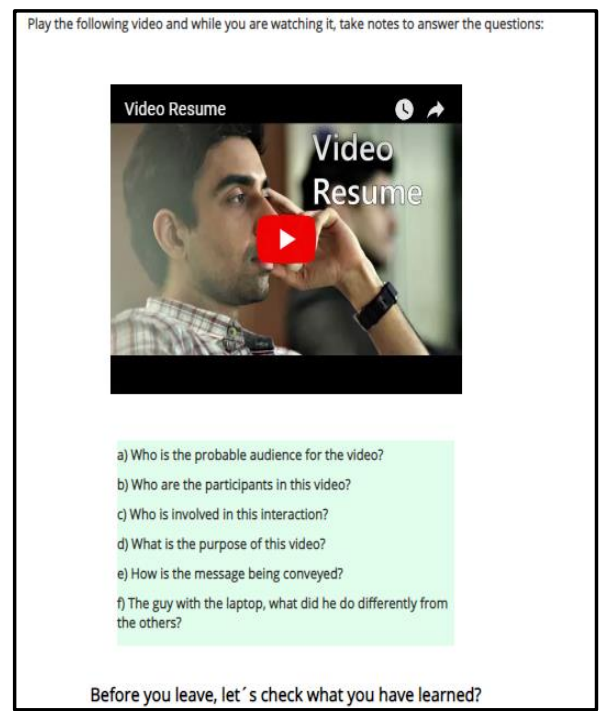

Fonte: ReSPonD - Banco de dados NuPEAD (2018) 
O momento Before Class torna-se consoante à pedagogia de gêneros (ROSE; MARTIN, 2012), pois no material didático digital quanto ao trabalho com gêneros, é que previmos contextualizar o aluno quanto ao contexto de produção e consumo e desconstruir os estágios, a fim de mostrar a linguagem em contexto social de ação.

Compreender os estágios do gênero tem como premissa mostrar a estrutura retórica, para levar o aluno a entender como este se organiza. É, por meio do registro da linguagem que o aluno identifica o contexto de uso nas diferentes práticas sociais, pois a linguagem constitui-se por meio de gêneros e por meio dela produzimos significados (HALLIDAY, 2004; REIS, 2010). Ao analisarmos o gênero quanto ao contexto de cultura e situação, de consumo, produção e disseminação, o aluno tem contato com a língua e identifica como ela é representada.

Após esse primeiro contato com o material, consideramos que o aluno deverá colocar um pouco mais em prática o que começou a estudar. Na figura 2, é possível identificar as atividades incluídas no momento During Class no estágio um. A primeira atividade de During Class, planejada como "ice breaking", é uma atividade para "quebrar o gelo" entre os participantes, colocando-os em contexto de produção oral a fim de potencializar o uso e a compreensão na língua adicional.

Outra atividade no momento During class, do estágio um, é o Let's work together, encontrada na seção For action, considerada como a atividade principal desse estágio. Essa é uma proposta de atividade colaborativa em que os alunos, após contextualização sobre o gênero vídeo résumé e acesso a uma apresentação pessoal de uma personalidade, são instruídos a pesquisarem sobre uma terceira pessoa, para posteriormente elaborar a primeira versão de um script com informações tais como idade, local de origem, hobbies, o que estuda e onde trabalha. A Figura 6 ilustra a atividade colaborativa do estágio um.

Figura 6 - Exemplo da atividade/Challenge Let's work together

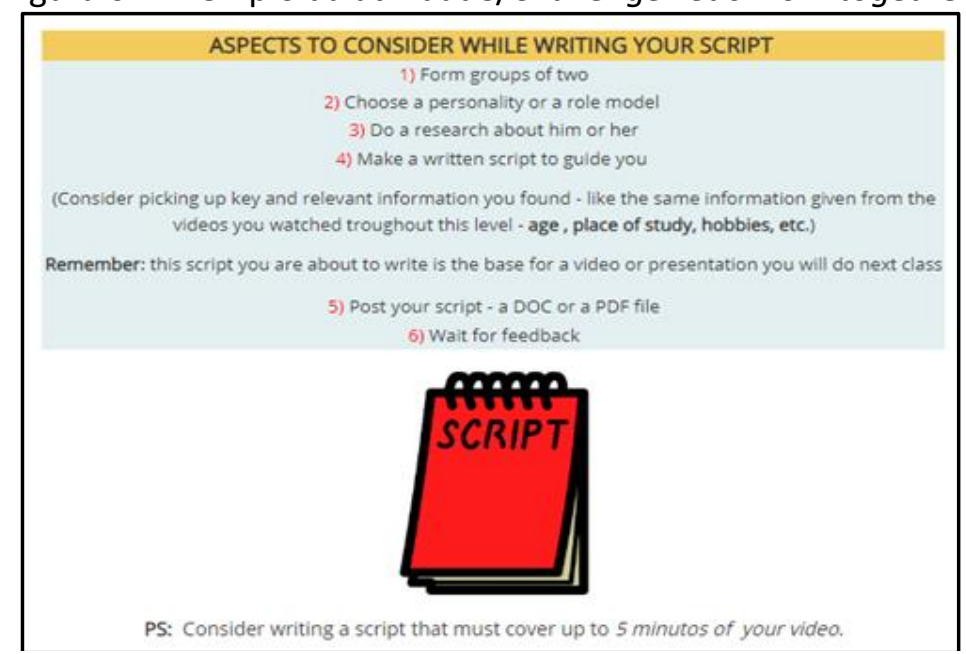

Fonte: Banco de dados NuPEAD (2018) 
Nessa etapa do material, a atividade colaborativa, proposta no momento For Action, é elaborada considerando o ciclo de aprendizagem (ROSE; MARTIN, 2012), pois previmos que após acessar o conteúdo exposto no Before Class, o aluno possa reconstruir o gênero identificando na atividade proposta, junto com os colegas, o contexto simulado de situações reais, para que possa praticar a língua adicional de modo significativo (MOTTA-ROTH, 2006; REIS, 2010) fazendo uso de habilidades orais e da escrita.

Com essa atividade, esperamos que o aluno desenvolvesse no ReSPOnD a produção oral, durante a interação com os colegas e ao apresentar oralmente ao reportar ao professor a pesquisa proposta e, por meio da produção escrita, escrever seu texto (script) sobre a terceira pessoa pesquisada. Desse modo, o aluno pratica as duas habilidades de forma integrada. Na tentativa de propormos uma atividade de pós-leitura e analisarmos o feedback do aluno quanto ao reconhecimento do gênero proposto e o contexto social em que ele se insere, elaboramos um quiz no Moodle com nove questões.

A seção After Class (Ver Figura 2) tem como objetivo consolidar o estudo do estágio após a aula presencial. Na página summing up apresentamos alguns resumos sobre o estágio que o aluno se encontra, seu objetivo e função. O momento After Class tem como premissa, também, reconstruir, de forma individual, o gênero proposto no momento During Class do estágio um. Espera-se que o aluno reproduza de forma independente a situação comunicativa self-presentation, atingindo assim um dos objetivos do curso que é promover a produção oral de forma integrada às atividades propostas no ReSPOnD, no ambiente online Moodle.

Exemplos de outras atividades e demais informações sobre o curso podem ser obtidas na dissertação de Pletsch (2018) que o descreve com mais detalhes o curso. Devido ao recorte deste trabalho, na sequência selecionamos alguns dados de avaliação sobre a proposta aplicada.

\section{Síntese da avaliação da versão piloto proposta}

Os resultados obtidos pelo questionário avaliativo e pelos dados registrados no diário de campo foram sintetizados a partir da avaliação de cinco participantes da testagem (Ptest). Embora os dados sejam relevantes como amostragem, não são suficientes para generalizarmos tais resultados. Em vista disso, selecionamos resultados que consideramos basilares para avaliar a proposta, haja vista repensarmos o redesign do curso e futuras aplicações.

Quanto ao design da primeira versão do ReSPOnd, os 5 Ptest avaliaram "o layout, a interface e a disposição dos elementos textuais/não textuais" como ótimo, pois na 
percepção deles, esses aspectos estão consoantes à proposta para o MDD na perspectiva de sala aula invertida (ver Figura 8).

Figura 8 - Pergunta de Avaliação - Questionário Avaliativo

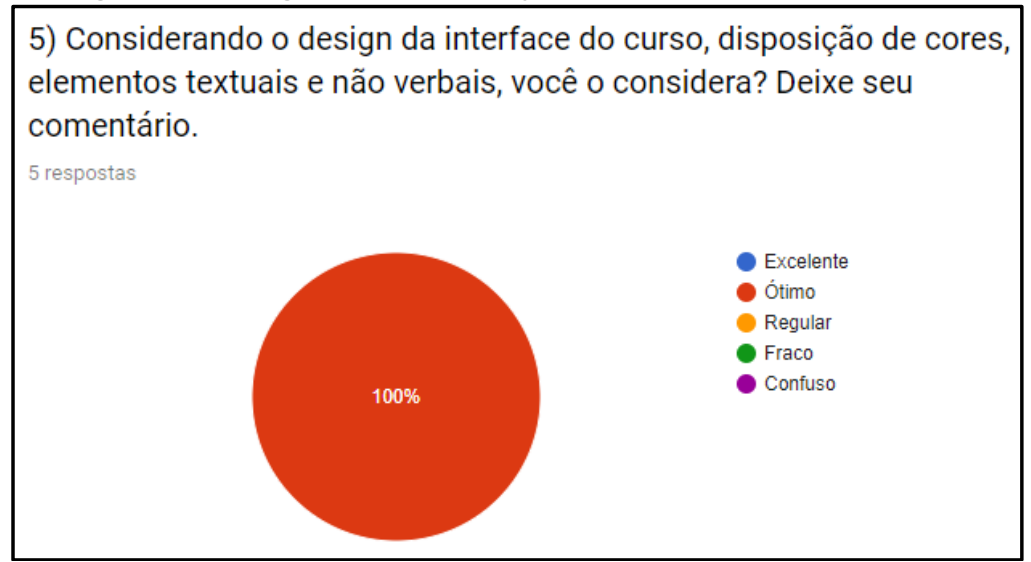

Fonte: Banco de dados NuPEAD (2018)

Avaliamos, também, em que medida o design do curso contemplou os estágios da sala de aula invertida, com relação aos momentos do curso "Before, during e after class", quanto esse item tivemos como feedback de 4 Ptests, os quais afirmaram que tais momentos mostraram-se "satisfatórios'. Apenas um dos participantes afirmou que "sentiu falta que os colegas não haviam estudado o momento Before class" (PLETSCH, 2018, p. 91).

Esse dado nos indica duas hipóteses. Primeiro, o design do estágio Before Class ainda não promoveu suficientemente o engajamento dos alunos no curso ou, em segundo lugar, nossos alunos não têm a cultura de estudo para que a abordagem sala de aula invertida seja completamente efetivada.

Entendemos que essa cultura não é tão simples de desenvolver em alunos brasileiros, já que, na maioria das vezes, nossos alunos não possuem o hábito de estudar antes de irem para aula, ainda mais um conteúdo de uma língua estrangeira, de modo autônomo e individual. Portanto, incluir ações ou estratégias no próprio design do material do curso, que recompense os alunos por essa prática, principalmente por resolverem as atividades dentro dos prazos ou, por solucionarem os desafios no momento "antes da aula", pode ser uma alternativa para esse minimizar esse problema de cultura de estudo.

Como grupo de pesquisa, trabalhamos com as estratégias de gamification (GOMES, 2017) dentro do design de cursos online como uma forma de instigar o engajamento e a motivação dos alunos em ambiente de cursos de ensino a distância. Nessa edição não tivemos tempo hábil para tais implementações. Para a próxima versão do ReSPOnd, temos como intenção implementar tais estratégias também no design, com vista a atingir melhor engajamento dos participantes no momento Before Class.

Quanto ao trabalho com gêneros, tivemos como resultado para quatro dos participantes que estudar o momento Before class "foi importante" para "ter contato com o 
conteúdo/gênero e apropriar-se do mesmo e ir preparado para a sala de aula" (PLETSCH, 2018 , p. 92). A figura 9 confirma a porcentagem de alunos que estudou tal momento:

Figura 9 - Pergunta de Avaliação

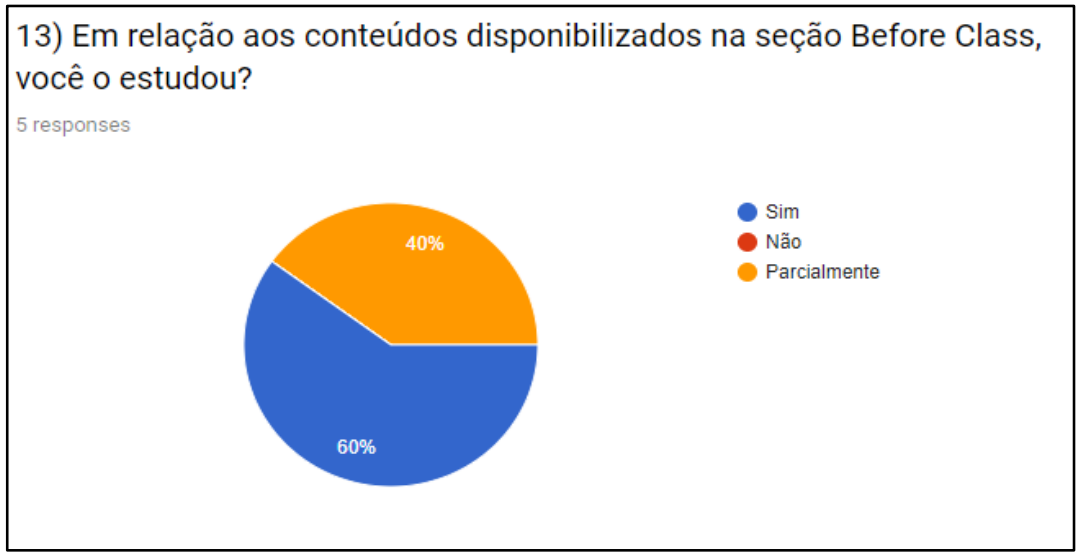

Fonte: Banco de dados NuPEAD (2018)

Para avaliarmos as atividades previstas no momento During Class, três participantes (PTest\#2; PTest\#3; PTest\#5) afirmaram que "o momento foi essencial para compreender o gênero proposto e desenvolver a compreensão oral". Para os outros dois, os participantes concluíram que esse momento "potencializou a prática colaborativa em sala de aula" (PLETSCH, 2018, p. 92) (ver Figura dez).

Figura 10 - Pergunta de Avaliação - Questionário Avaliativo

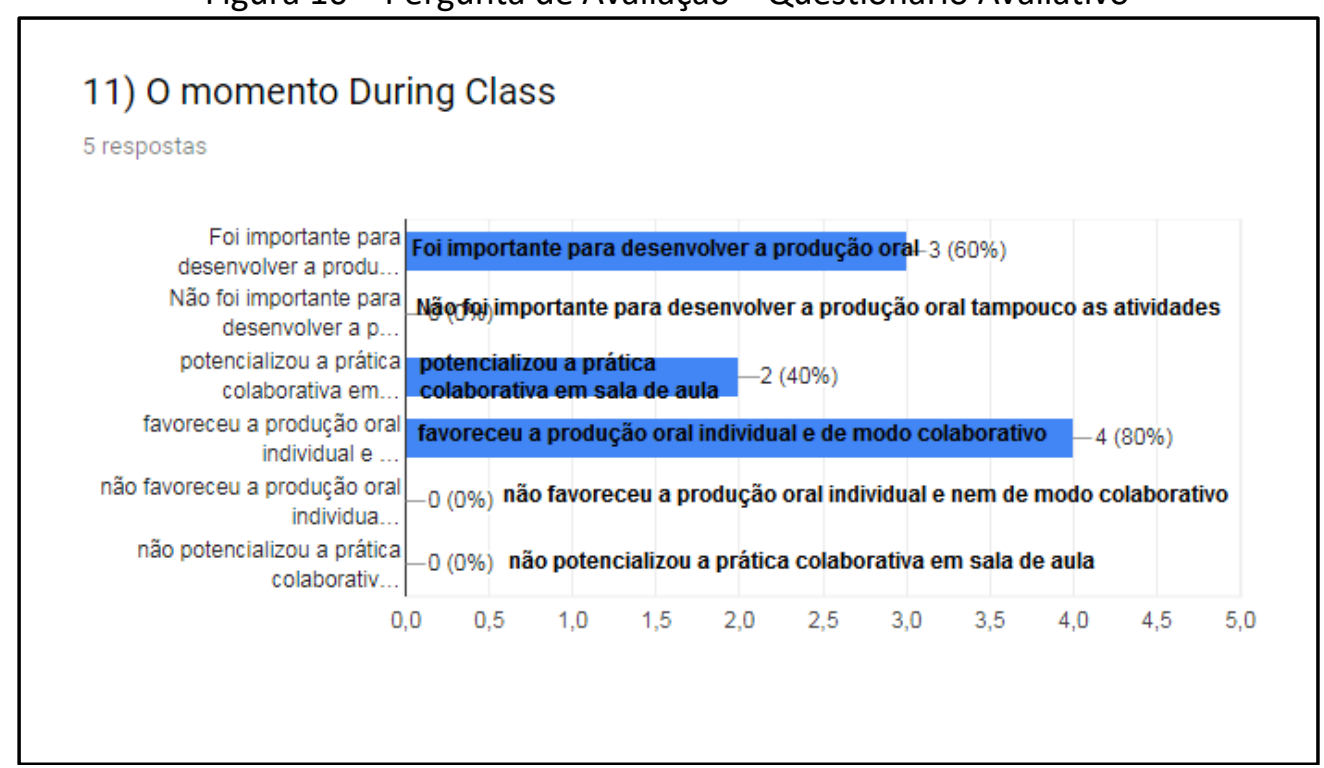

Fonte: Banco de dados NuPEAD (2018)

Ao avaliarmos as ferramentas digitais, como estas auxiliaram de forma satisfatória para o desenvolvimento das atividades no decorrer das trinta horas previstas para a execução do curso (PLETSCH, 2018, p. 95). Os participantes afirmaram que a ferramenta 
Online Voice Recorder e We Vídeo aprimoraram a compreensão e produção oral, bem como o Google Drive contribuiu para as atividades de produção escrita. Os vídeos disponibilizados no Youtube permitiram aperfeiçoar ainda a compreensão oral (PLETSCH, 2018, p. 95), conforme ilustram dados da Figura 11.

Figura 11 - Perguntas de Avaliação

\begin{tabular}{|c|c|}
\hline Online Voice Recorder e WeVideo permitiram aprimorar a compreensão oral & $80 \%$ \\
\hline Google Drive permitiu aprimorar a compreensão escrita & $80 \%$ \\
\hline Online Voice Recorder e WeVideo permitiram aprimorar a produção oral & $60 \%$ \\
\hline Vídeos disponibilizados a partir do Youtube permitiram aprimorar a compreensão oral & $80 \%$ \\
\hline
\end{tabular}

Fonte: Banco de dados NuPEAD (2018)

Quanto ao momento After Class, neste potencializou-se a produção individual, e os cinco Ptest concluintes relataram que "foi importante para promover a síntese do conteúdo e das atividades propostas" (PLETSCH, 2018, p. 93). Os dados da Figura 12 ilustram essa questão:

Figura 12 - Pergunta de Avaliação

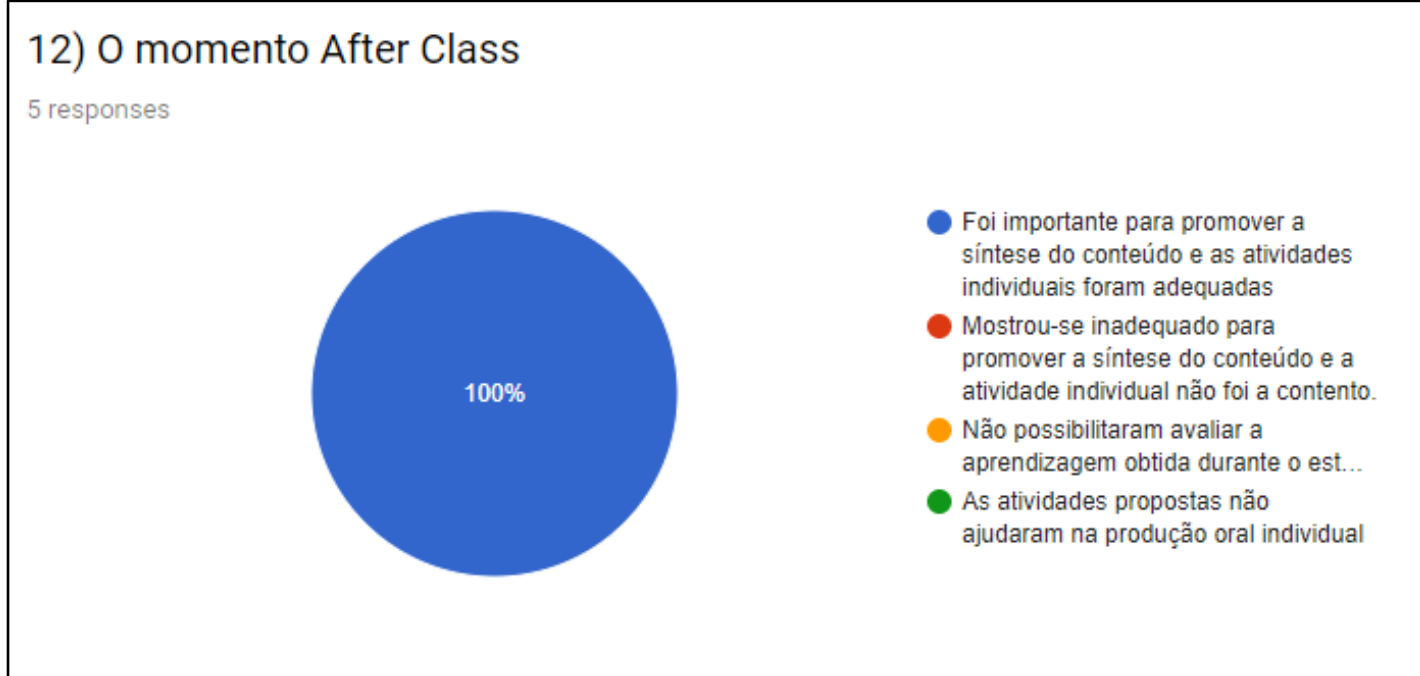

Fonte: Banco de dados NuPEAD (2018)

Por conseguinte, podemos inferir que os momentos previstos na perspectiva da SAI permitem a prática de atividades, colocando o aluno no centro do processo e as propostas planejadas alcançaram o objetivo de potencializar a o uso da língua adicional de forma conjunta e integrada. Embora, notamos que são necessários ajustes no design e nas 
propostas elaboradas para a versão piloto, concebemos que o curso conseguiu estruturar um material didático digital que explora as teorias propostas.

\section{Considerações finais}

O material didático digital ReSPOnD, em estágio de Re(design), mostrou-se válido para implementar a abordagem sala de aula invertida, bem como as atividades propostas corroboraram para o desenvolvimento das habilidades de produção e de compreensão oral, leitura e escrita de forma integrada. Porém, os dados evidenciaram que se faz necessário melhor investigar como engajar os alunos no momento Before Class para que este seja totalmente efetivo, assim como mitigar a necessidade de abrir espaço de melhor prática efetiva nas atividades During Class.

Como alternativa, planejamos integrar no design as estratégias de para fomentar o melhor engajamento dos alunos no estágio. Como previsto na SAI, é preciso promover a cultura de estudar os conteúdos/gêneros antes da aula presencial, bem como propor atividades que explorem de modo mais efetivo as habilidades de leitura, de forma mais dinâmica e integrada às outras habilidades.

$\mathrm{Na}$ tentativa de responder a pergunta de pesquisa - como propor um material didático digital em língua inglesa, na perspectiva da sala de aula invertida, que possibilite efetivar a produção oral em uma abordagem de ensino de linguagem em gêneros? Podemos concluir que o ReSPOnD traz uma alternativa, no entanto, requer-se mais estudos que busquem reaplicar o curso em outros contextos, bem como explorar ainda outras propostas de atividades utilizando o Moodle como plataforma de ensino.

Com relação à pergunta de pesquisa "Os momentos antes, durante e após a aula, previstos na abordagem Sala de Aula Invertida (doravante SAI), são efetivos para potencializar a prática da língua adicional na modalidade híbrida?", podemos afirmar que a experiência destaca o reconhecimento dos participantes por esses momentos, e, também, a necessidade de motivar os alunos em resolver os desafios proposto no momento Before Class para que as atividades práticas em sala de aula sejam realmente dinâmicas, efetivas e significativas.

As tarefas/gêneros descritas exemplificam a proposta teórico-pedagógica do ReSPOnd e o trabalho realizado, e reforçam a necessidade do professor como designer de aprendizagens dar devida atenção ao planejamento do material didático digital, considerando que tanto as aulas quanto o MDD precisa ser pensado, planejado sistematicamente considerando os interesses dos alunos. Para isso, é preciso favorecer a prática de multiletramentos, promover os processos de produção de conhecimentos, sugeridos por Cope e Kalantzis (2009), em que se deve considerar o que o aluno já sabe para 
levá-lo a novas descobertas, a assimilação e a aprendizagem de novos conteúdos de modo crítico (REIS, 2018).

Ao considerar os momentos da SAI em outros designs de cursos on-line, sugerimos que o Before Class, seja bem planejado, pois esse é o primeiro contato do discente com o conteúdo, para isso, é essencial na fase de análise e de planejamento do MDD investigar a realidade dos alunos; a fim de posteriormente encontrar estratégias que busquem no material tornar o engajamento do discente naturalizado. Para isso, é preciso propor atividades que desafiem o aluno a agir, utilizando ferramentas automáticas de feedback, que valorizem cada descoberta ou clique do aluno no curso, para evidenciar se o aluno está compreendendo o material exposto, mediante atividades de checagem e recursos que permitam evidenciar os logs de acesso do aluno no ambiente virtual, antes da aula presencial.

\section{Referências}

ALLEN, M. Creating Successful e-Learning: A rapid system for Getting It Right First Time, Every Time. São Francisco: Pfeiffer. 2006.

BACICH, L.; NETO, A. T.; TREVISANI, F. M. Ensino híbrido: personalização e tecnologia na educação. Porto Alegre: Penso, 2015.

BEHAR, P. A.; MACEDO, A.L ; AMARAL, C.B ; TORREZZAN, C. A. W. ; SCHNEIDER, D. ; LONGHI, M. ; BERCHT, M. ; BERNARDI, M. ; BECKER, M. L. R. ; NOTARE, M. ; WALQUIL, M. ; LEITE, S.M. ; MORESCO, S.F.S. ; FROZI, A.P . Modelos Pedagógicos em Educação a Distância. 1. ed. Porto Alegre: ArtMed, 2009. v. 1. 311p.

BERGMANN, J.; SAMS, A. Sala de aula invertida: uma metodologia ativa de aprendizagem. Rio de Janeiro: LTC, 2016.

BOTTENTUIT JUNIOR, J.B.; MENDES, A.G.L.M; SILVA, N.M. Sala de Aula Invertida e Tecnologias Digitais: uma experiência numa Escola Pública em São Luís - MA. Revista Tecnologias na Educação, v. 18, p. 1-15, 2017.

CECCHIN. A. S. Práticas de multiletramentos no contexto escolar: investigação de uma abordagem para o ensino de produção de narrativas digitais. 2015. 168 p. Dissertação (Mestrado em Tecnologias Educacionais em Rede) - Universidade Federal de Santa Maria, Santa Maria, 2016.

CECCHIN. A. S; REIS, S.C. Investigação de uma abordagem para o ensino de produção de narrativas digitais: um estudo com foco em práticas de multiletramentos no contexto escolar público. Veredas (UFJF. Online), v. 20, p. 38-58, 2016.

CHRISTENSEN, C. M.; HORN, M. B.; STAKER, H. Ensino híbrido: uma inovação disruptiva? Uma introdução à teoria dos híbridos. [S.I: s. n], 2013. Disponível em: <http://porvir.org/wpcontent/uploads/2014/08/PT_Is-K-12-blended-learning-disruptive-Final.pdf>. Acesso em: 03 jul. 2017. 
COPE, B.; KALANTZIS, M. Multiliteracies: new literacies, new learning. Pedagogies: an Internacional Journal, v. 4, n. 3, p. 164-195, 2009.

https://doi.org/10.1080/15544800903076044

GOMES, A. F. Material didático digital, games e gamification: conexões no design para implementação de cursos online. 2017, 209f. Dissertação (Mestrado) - Universidade Federal de Santa Maria, Centro de Educação, Programa de Pós-Graduação em Tecnologias Educacionais em Rede, Santa Maria, RS, 2017.

HALLIDAY, M. A. K. An introduction to functional grammar. 3rd. ed. London: Edward Arnold, 2004.

HALLIDAY, M. A. K.; HASSAN, R. Language, context and text: aspects of language in a socialsemiotic perspective. Oxford: Oxford University, 1989.

LEFFA, V. J. Produção de materiais de ensino: teoria e prática. 2. ed. rev. Pelotas: Educar, 2008.

LIRA, B. C. Práticas pedagógicas para o século XXI: a sociointeração digital e o humanismo ético. Petrópolis, RJ: Vozes, 2016.

FILATRO, A. Design instrucional na prática. 1. ed. São Paulo: Pearson Editora, 2008.

MAZON, M. BLENDED LEARNING E OS DESAFIOS NO ENSINO SUPERIOR Proposta da sala de aula invertida mediada pelas TIC's. Anais do Seminário de Pesquisa, Pós-Graduação e Inovação - $\quad$ SPPI, [S.I.], jan. 2016. Disponível em: $<$ https://publicacoes.rexlab.ufsc.br/index.php/sppi/article/view/41>. Acesso em: 12 ago. 2018.

MORAN, J. Educação híbrida: um conceito-chave para a educação, hoje. In: BACICH, L.; NETO, A. T.; TREVISANI, F. M. (Org.). Ensino híbrido: personalização e tecnologia na educação. Porto Alegre: Penso, p. 27-45, 2015.

MOTTA-ROTH, D. Para ligar a teoria à prática: roteiro de perguntas para orientar a leitura/análise crítica de gêneros. In: MOTTA-ROTH, D.; CABAÑAS, T.; HENDGES, G. (Orgs.). Análises de textos e de discursos: relações entre teorias e práticas. Santa Maria: PPGL Editores, p. 243-272, 2008. https://doi.org/10.1590/S0102-44502008000200007

MOTTA-ROTH, D. O ensino de produção textual com base em atividades sociais e gêneros textuais. Revista Linguagem em Discurso v. 6, n. 3, p. 495-517, 2006.

MOTTA-ROTH, D. Questões de metodologia em análise de gêneros. In: KARWOSKI, A.M.; GAYDECKA, B.; BRITO, K.S. (Org.). Gêneros textuais: Reflexões e ensino. 2. ed. rev. e aum. Rio de Janeiro: Lucerna, 2006. p. 145-163

MOTTA-ROTH, D. Análise crítica de gêneros: contribuições para o ensino e a pesquisa de linguagem. DELTA. Documentação de Estudos em Linguística Teórica e Aplicada (Online), v. 24, p. 341-383, 2008.

MOORE, M. G.; KEARSLEY, G. Educação a distância: uma visão integrada. São Paulo: Cengage Learning, 2008.

PLETSCH, E. Desenvolvimento de material didático digital de língua inglesa na perspectiva de sala de aula invertida. 2018. 149 p. Dissertação (Mestrado em Tecnologias Educacionais em Rede) - Universidade Federal de Santa Maria, Santa Maria, RS, 2018. 
REIS, S. C. Ensino de produção oral em língua inglesa por meio de podcast: relatando uma experiência com alunos do ensino fundamental. Veredas - Revista de Estudos Linguísticos, v. 21, p. 180-201, 2017.

REIS, S. C. Produção de material didático digital: princípios para orientar o design de cursos de língua online. 2018 (no prelo).

REIS, S. C.; GOMES, A. F. Podcasts para o ensino de Língua Inglesa: análise e prática de Letramento Digital. Calidoscópio, v. 12, p. 367-379, 2014.

https://doi.org/10.4013/cld.2014.123.11

REIS, S. C. Do discurso à prática: textualização de pesquisas sobre o ensino de inglês mediado por computador. 2010. 242f. Tese (Pós-Graduação em Letras, Área de Estudos Linguísticos) Universidade Federal de Santa Maria, RS, 2010.

REIS, S. C.; GOMES, A. F; SOUZA, R. S. O Ensino e a aprendizagem de línguas mediado por computador: conectando teoria e prática em um jogo. Revista Eletrônica de Linguística (UFU. Online), v. 6, p. 137-149, 2012. https://doi.org/10.14393/DL13-v6n2a2012-9

REIS, S. C.; LINCK, A. J.; MATTIELLO, L. English 3D: uma proposta de curso de inglês a distância no projeto LabEOn. In: XVIII CONFERÊNCIA INTERNACIONAL DE INFORMÁTICA NA EDUCAÇÃO (TISE), 2013, Porto Alegre. Anais.... Porto Alegre, 2013. p. 353-359.

ROSE, D; MARTIN, J. R. Learning to write, Reading to learn. Equinox: UK, 2012.

SCHNEIDER, F. Otimização do espaço escolar por meio do modelo de ensino híbrido. In: BACICH, L.; NETO, A. T.; TREVISANI, F. M. (Org.) Ensino hibrido: personalização e tecnologia na educação. Porto Alegre: Penso, 2015. p. 67-80.

VALENTE, J. A.; ARANTES, V. A.; MORAN COSTAS, J. M. Educação a Distância: Pontos e Contrapontos. 1. ed. São Paulo: Summus Editorial, 2011.

VALENTE, J. A. Blended Learning e as Mudanças no Ensino Superior: a proposta da sala de aula invertida. Educar em Revista (Impresso), v. Especial 4, p. 79-97, 2014. https://doi.org/10.1590/0104-4060.38645

VYGOTSKY, L. S. Pensamento e linguagem. São Paulo: Martins Fontes, 1989.

Recebido em: 23/10/2018

Aceito em: 05/01/2019 